\title{
Skepticism and pharmacophobia toward
} medication may negatively impact adherence to psychiatric medications: a comparison among outpatient samples recruited in Spain, Argentina, and Venezuela

\author{
Carlos De las Cuevas' \\ Mariano Motuca ${ }^{2}$ \\ Trino Baptista ${ }^{3}$ \\ Jose de Leon ${ }^{4-6}$ \\ 'Department of Internal Medicine, \\ Dermatology and Psychiatry, \\ Universidad de La Laguna, Canary \\ Islands, Spain; 'Instituto Vilapriño, \\ Center for Studies, Assistance \\ and Research in Neurosciences, \\ Mendoza, Argentina; ${ }^{3}$ Departament \\ of Physiology, Facultad de Medicina, \\ Universidad de Los Andes, Mérida, \\ Venezuela; ${ }^{4}$ Mental Health Research \\ Center at Eastern State Hospital, \\ Lexington, KY, USA; ${ }^{5}$ Psychiatry and \\ Neurosciences Research Group \\ (CTS-549), Institute of Neurosciences, \\ University of Granada, Granada, \\ Spain; ${ }^{6}$ Biomedical Research Centre \\ in Mental Health Net (CIBERSAM), \\ Santiago Apostol Hospital, University \\ of the Basque Country, Vitoria, Spain
}

Correspondence: Carlos De las Cuevas Departamento de Medicina Interna, Dermatología y Psiquiatría, Universidad de La Laguna, Campus de Ofra, 3807I

San Cristóbal de La Laguna, Spain

Tel +34609521 405

Email cdelascuevas@gmail.com
This article was published in the following Dove Press journal: Patient Preference and Adherence

Background: Cultural differences in attitudes toward psychiatric medications influence medication adherence but transcultural studies are missing. The objective of this study was to investigate how attitudes and beliefs toward psychotropic medications influence treatment adherence in psychiatric outpatients in Spain, Argentina, and Venezuela.

Methods: A cross-sectional, cross-cultural psychopharmacology study was designed to assess psychiatric outpatients' attitudes toward their prescribed medication. Patients completed the Drug Attitude Inventory - 10 Item (DAI-10), the Beliefs about Medicines Questionnaire - Specific Scale (BMQ-Specific), the Sidorkiewicz adherence tool, and sociodemographic and clinical questionnaires. The study included 1,291 adult psychiatric outpatients using 2,308 psychotropic drugs from three Spanish-speaking countries, the Canary Islands (Spain) (N=588 patients), Argentina $(\mathrm{N}=508)$, and Venezuela $(\mathrm{N}=195)$.

Results: The univariate analyses showed different mean scores on the DAI-10 and the BMQ Necessity and Concerns subscales but, on the other hand, the percentages of non-adherent and skeptical patients were relatively similar in three countries. Argentinian patients had a very low level of pharmacophobia. Multivariate analyses (logistic regression and chi-squared automatic interaction detector segmentation) showed that pharmacophobia in general and skepticism about specific medications (high concern about adverse reactions and low belief in their necessity) were associated with non-adherence. Pharmacophobia was the major factor associated with nonadherence (Spain and Venezuela) but when pharmacophobia was rare (Argentina), skepticism was the most important variable associated with non-adherence.

Conclusion: Psychiatric patients' attitudes and beliefs about their psychiatric treatment varied in these three Spanish-speaking countries, but pharmacophobia and skepticism appeared to play a consistent role in lack of adherence.

Keywords: attitude to health, medication adherence, health behavior, model, statistical, psychiatry

\section{Plain language summary}

Why was the study done? There are factors that influence whether psychiatric patients take their medications or not and they vary among countries.

What did the researchers do? They studied 1,291 adult psychiatric outpatients using 2,308 psychotropic drugs who were treated in three Spanish-speaking countries: the Canary 
Islands (Spain), Argentina, and Venezuela. In these patients, they studied: 1) sociodemographic measures, 2) clinical measures, 3) measures of attitude toward psychiatric medications, 4) beliefs about necessity and concern about their psychiatric drug treatments, and 5) self-reports from patients about adherence or lack of adherence to psychiatric prescriptions. All of these measures were explored using mathematical models.

What did the researchers find? Negative attitude toward medications (pharmacophobia) was the major factor associated with non-adherence to medications (Spain and Venezuela), but when pharmacophobia was rare (Argentina), having a skeptical view of specific medications was the most important variable associated with medication adherence in psychiatric patients.

What do these results mean? The attitudes and beliefs of psychiatric patients about their psychiatric treatment play a major role in adherence to medications. Cultural differences may influence the specific profile of beliefs and attitudes about psychiatric drugs.

\section{Introduction}

Ethnopsychopharmacology is the subspecialty of psychopharmacology that studies how differences in social groups influence response to psychiatric medications. ${ }^{1-3}$ These differences in drug response can be biological (interethnic pharmacokinetic and pharmacodynamic variations resulting from genetic polymorphisms) and/or cultural., ${ }^{4,5}$

According to a meta-analytic review, ${ }^{6}$ psychiatric patients prefer psychological to pharmacological treatments. However, the prescription of psychoactive medication, alone or associated with psychotherapy, is the most common intervention in mental health care. ${ }^{7}$ Different cultural groups may have different beliefs about psychiatric medications, thus influencing their attitudes toward them. Therefore, assessment of attitudes toward psychiatric drug treatment, which are influenced by cultural beliefs, may help to improve therapeutic alliance and patients' adherence to prescribed treatment and allow the planning of appropriate interventions for optimizing treatment outcomes in patients from different cultures. ${ }^{8}$

Spain, Argentina, and Venezuela are among the most populous Spanish-speaking countries in the world. But despite sharing part of their history and having the same official language, the three countries are quite different in terms of culture. Moreover, multiculturalism and multiethnicity generated by frequent migrations in these countries make it necessary to pay more attention to the clinical needs of ethnic minority populations and to focus research toward the psychiatric needs of multiethnic groups. Concerning health care systems, a recent report ${ }^{9}$ rating 195 countries in terms of their quality and access to health care during the last 25 years has ranked the Spanish health care system as 8th (with a total score of 90/100), while Argentina was 62nd (68/100) and Venezuela 96th (65/100).

At present, we do not have enough studies that analyze the clinical, social, and cultural differences in attitudes toward psychiatric medications in these three Spanish-speaking countries. If different cultural attitudes toward psychiatric drug treatment exist, they should influence the type of treatment sought and how psychiatric disorders should be addressed and managed for different ethnic groups. ${ }^{10}$ In our studies in the Canary Islands, an area within Spain, we have found that different attitudes toward medication led to different cognitive styles, which may influence medication adherence to psychiatric medication, while clinical variables may not be so important. These initial Spanish studies suggest that pharmacophobia (aversion to taking medications) is associated with poor adherence. Concerns about adverse drug reactions (ADRs) and the perceived necessity of taking medications also appear important regarding adherence. Moreover, patients with skepticism about specific medications (high concern for ADRs and low belief in the necessity of taking these medications) appear to be more prone to poor adherence. ${ }^{11,12}$

These attitudes toward medication found in the Canary Islands should also exist in Argentina and Venezuela, although their prevalence may vary based on different cultural beliefs. Therefore, the main and exploratory aim of this study was to investigate from a cross-cultural/transcultural design attitudes and beliefs of psychiatric outpatients in three Spanish-speaking countries toward their prescribed psychotropic treatment as well as their influence on adherence to prescribed treatment. The second and confirmatory aim is to verify our findings in the Canary Islands that pharmacophobia and skepticism are important variables associated with poor adherence.

\section{Methods}

\section{Study design and participants}

The ethics committee of the Canary Islands Health Service approved this study, and all the participating patients provided written informed consent. This cross-sectional, cross-cultural psychopharmacology study was completed at outpatient psychiatric services in the Canary Islands (Spain), Mendoza (Argentina), and Mérida (Venezuela). The inclusion criteria for the psychiatric outpatients were as follows: 1) 18 years or older, 2) able to read and understand Spanish, 3) diagnosed with a psychiatric disorder, 4) treated with at least one psychiatric drug, and 5) participating voluntarily. 


\section{Instruments}

\section{Drug Attitude Inventory - 10 Items}

Psychiatric outpatients' attitudes toward their prescribed psychotropic medications were measured using the "Drug Attitude Inventory - 10 Items" (DAI-10) scale. ${ }^{13,14}$ The purpose of this self-administered scale is to understand how patients view the use of their psychiatric medications and the nature of their experiences with these psychoactive drugs, through 10 items with response options as true/false. Each response is scored as +1 if marked true or -1 if marked false and the final score is the sum of the score of each of the 10 items ranging from -10 (very poor attitude) to +10 (best possible attitude). Patients were grouped according to their DAI-10 total score. Those who had 0 or negative scores were classified as "pharmacophobic" and those with a total score of more than 0 were classified as "pharmacophilic". ${ }^{15}$ Each patient completed the DAI-10 on a single occasion based on global assessment of their prescribed psychopharmacological treatment.

\section{Beliefs about Medicines Questionnaire - Specific Scale}

Psychiatric patients' perceptions of their personal need for treatment, called necessity beliefs, and their concerns and beliefs about the potential negative effects of taking medicines, were measured using the Beliefs about Medicines Questionnaire - Specific Scale (BMQ-Specific) ${ }^{16,17}$ The scale includes 10 items on two subscales: Concern and Necessity, each with five items. The degree of agreement with each statement is indicated on a five-point Likert scale, ranging from $1=$ strongly disagree to $5=$ strongly agree. The Necessity Concerns Framework has been demonstrated to be a useful conceptual model for understanding patients' perspectives on prescribed medicines. The model enhances the quality of prescribing by helping clinicians to engage patients in treatment decisions and support optimal adherence to appropriate prescriptions. ${ }^{18,19}$ Every patient completed one BMQ-Specific scale for each psychoactive drug consumed.

\section{Four attitudinal groups based on Necessity and Concern subscales}

Participants were categorized into attitudinal group $\mathrm{s}^{20}$ based on their beliefs about their psychiatric medications. The Necessity and Concerns subscales were split at the median to generate four attitudinal groups: Accepting (high necessity, low concern), Ambivalent (high necessity, high concern), Indifferent (low necessity, low concern), and Skeptical (low necessity, high concern). ${ }^{21}$

\section{Sidorkiewicz adherence tool}

Medication adherence was assessed using the Spanish version of the validated Sidorkiewicz instrument to assess treatment adherence for each individual drug taken by a patient. ${ }^{22,23}$ This instrument contains five questions with two or three possible answers, illustrated with practical examples and pictographs, to help patients recognize their different medication-taking behaviors for each drug taken. The major advantage of the Sidorkiewicz tool is allowing clinicians to identify how patients adhere to drugs during polypharmacy. ${ }^{23}$

\section{Data analysis}

Data management and analyses were carried out using the statistical software package Statistical Package for the Social Sciences (SPSS) version 24. ${ }^{24}$ Two types of analyses were carried out:

1. Multiple univariate exploratory analyses with a descriptive purpose included: the distribution of frequencies and percentages for qualitative variables; data exploration with normal-fit QQ graph, histogram, asymmetry coefficients, and kurtosis/height together with the Kolmogorov-Smirnov goodness-of-fit test (which was considered to be a mismatch only if $p<0.010)$ and description with the usual centrality (mean, median) and variability (standard deviation, range: $\mathrm{min} / \mathrm{max}$, and interquartile range) for quantitative variables; and tests of difference of means (Student's $t$-test and ANOVA) next to its nonparametric alternatives (Mann-Whitney and Kruskall-Wallis) and chi-square. Multiple exploratory significance tests without Bonferroni correction were carried out since the samples were expected to be heterogeneous. Many published articles including our recent methodological study on the Spanish version of the Sidorkiewicz instrument ${ }^{23}$ classify patients as adherent or non-adherent, which is more compatible with the language of clinicians. To follow that pattern, the high (1), good (2), and moderate (3) levels included in the Sidorkiewicz tool were considered "adherent", while the poor (4), very poor (5), and discontinuation (6) levels were considered "non-adherent".

2. Two multivariate confirmatory analyses, binary logistic regression and a chi-squared automatic interaction detector (CHAID) segmentation tree using treatment adherence as a dichotomous dependent variable, tried to verify that despite differences in the univariate analyses, pharmacophobia and skepticism are also associated with poor adherence in Argentina and Venezuela after correcting for confounding variables (sex and age). Therefore, based on 
our prior studies in the Canary Islands, the independent variables entered in the logistic regression were sex, age, pharmacophobia (yes/no), and skepticism (yes/no). The data mining technique of decision tree analysis was carried out to identify in these psychiatric patients the specific elements of adherence to prescribed treatment related to variables in the health belief model.

First a CHAID was used to build classification trees in the global sample using a systematic algorithm to detect the strongest association between predictors (country, sex, age, pharmacophobia, and skepticism) and the outcome variable (adherence to prescribed treatment) through a comprehensive search of the predictors and the levels of predictors from the entire set that show the most differentiation in the outcome variable. Then a CHAID was used to build classification trees for each country using a similar algorithm but without the country among the predictors. The degree of differentiation is represented sequentially in a decision tree format to show the optimally split predictors. ${ }^{25}$ The usual confidence level of 5\% (significant if $p<0.050$ ) was set for the logistic regression and the CHAID segmentation tree.

\section{Results}

\section{Exploratory descriptive analyses}

From April to November 2017, 1,291 consecutive psychiatric outpatients were recruited from mental health outpatient services in Spain, Argentina, and Venezuela. They were using 2,308 psychotropic drugs. Table 1 shows their sociodemographic and clinical variables including, in the combined sample, a mean age of 44.1 years, $\sim 58 \%$ were women, $44 \%$ completed secondary school, and $32 \%$ had a university degree. The most important main diagnoses were schizophrenia (18\%), bipolar disorder (11\%), depressive disorders (41\%), anxiety disorders (24\%), and personality disorders (6\%). Patients took a total of 2,308 medications; the most important classes were antidepressants in $37 \%$ of patients, antianxiety benzodiazepines in $28 \%$, antipsychotics in $22 \%$, and mood stabilizers in $13 \%$. The mean number of different psychoactive drugs prescribed per patient was 1.8. Global self-reported adherence, based on percentage, according to the Sidorkiewicz adherence tool at the drug level of the 2,308 drugs, disregarding who took them, was high in $44 \%$, good in $7 \%$, moderate in $15 \%$, poor in $12 \%$, and very poor in $7 \%$; drug discontinuation occurred in $16 \%$.

Pharmacophobic/pharmacophilic rates registered significant differences among participating countries with Argentine patients self-reporting the most positive attitude and Spanish patients the least positive attitude. Significant differences were registered in psychiatric patients' perceptions of personal need for treatment, or necessity beliefs, and concerns and beliefs about the potential negative effects of taking medications among the three countries (Table 2). Box 1 presents the highlights of Table 2, especially for clinicians.

Attitudes toward prescribed drug treatment were clearly related to patients' self-reported adherence, both globally and by country (Table 3 ). The four attitudinal groups from the Necessity-Concerns Framework registered significant differences in adherence to prescribed medication, independent of patient's country of origin, such that treatment adherence was highest in accepting patients and lowest in skeptical ones. Box 2 presents the highlights of analyses of the DAI-10 and BMQ described in Table 3 for clinicians.

\section{Multivariate analyses exploring effects of pharmacophobia and skepticism}

We proceeded to a multivariate study of the global sample using binary logistic regression models with adherence in its dichotomous form as the dependent variable. As the univariate results showed that the three countries demonstrated significant differences, after the global model, we proceeded to perform three binary logistic regression models, one for each country (Table 4). The statistical model parameters indicated the models were very effective in predicting adherence, but not so much in the prediction of non-adherence to prescribed treatment (see footnote $\mathrm{c}$ in Table 4). From the logistic regression models, the global model demonstrated that, as predicted, pharmacophobia (odds ratio $[\mathrm{OR}]=1.66$, 95\% confidence interval [CI] 1.34-2.06) and skepticism $(\mathrm{OR}=2.22$, CI 1.82-2.71) were significantly associated with poor adherence. Pharmacophobia was significant in all three countries, while skepticism did not reach significance in the smaller Venezuelan sample. The Argentinian sample appears to provide the most unexpected findings since pharmacophobia was significant $(p=0.005$ ) in spite of the small number of pharmacophobic patients $(9 \%)$, while skepticism had a particularly strong OR (=4.39) with a CI (3.10-6.22) that did not overlap with the Spanish CI (1.18-2.06) or the Venezuelan CI (0.79-2.50), indicating that in Argentinian patients skepticism has a significantly stronger effect on poor adherence than in the two other countries.

Figure 1 provides the results from the CHAID analysis in the global samples, which appeared similar to the logistic regression models in that 1) Spanish and Venezuelan samples appear closer since they grouped together in the first node, and 2) skepticism appears extremely important in Argentina for predicting poor adherence. The trees for each country 
Table I Sociodemographic and clinical characteristics of the samples studied (I,29I psychiatric patients, 2,308 psychiatric drugs used)

\begin{tabular}{|c|c|c|c|c|c|}
\hline & $\begin{array}{l}\text { Global } \\
\mathbf{N}=|, 29|\end{array}$ & $\begin{array}{l}\text { Spain } \\
n=588\end{array}$ & $\begin{array}{l}\text { Argentina } \\
\mathrm{n}=508\end{array}$ & $\begin{array}{l}\text { Venezuela } \\
n=\mid 95\end{array}$ & $p$-value \\
\hline Age, years & $44.1 \pm 14.2$ & $45.6 \pm 13.1$ & $42.1 \pm 15.5$ & $44.5 \pm 13.3$ & $0.000^{\mathrm{a}}$ \\
\hline $18-35$ & $31 \%$ & $24 \%$ & $40 \%$ & $29 \%$ & \\
\hline $35-50$ & $34 \%$ & $39 \%$ & $28 \%$ & $35 \%$ & \\
\hline $50-65$ & $28 \%$ & $30 \%$ & $24 \%$ & $31 \%$ & \\
\hline$>65$ & $7 \%$ & $7 \%$ & $8 \%$ & $5 \%$ & \\
\hline Sex & & & & & $0.000^{\mathrm{b}}$ \\
\hline Male & $42 \%$ & $47 \%$ & $34 \%$ & $47 \%$ & \\
\hline Female & $58 \%$ & $53 \%$ & $66 \%$ & $53 \%$ & \\
\hline Educational level & & & & & $0.000^{\mathrm{b}}$ \\
\hline Can read and write & $1 \%$ & $3 \%$ & $0 \%$ & $1 \%$ & \\
\hline Primary school & $23 \%$ & $27 \%$ & $19 \%$ & $19 \%$ & \\
\hline Secondary school & $44 \%$ & $44 \%$ & $48 \%$ & $34 \%$ & \\
\hline University & $32 \%$ & $26 \%$ & $36 \%$ & $47 \%$ & \\
\hline Diagnosis & & & & & $0.000^{\mathrm{b}}$ \\
\hline Schizophrenia & $18 \%$ & $23 \%$ & $6 \%$ & $31 \%$ & \\
\hline Bipolar disorder & $11 \%$ & $7 \%$ & $12 \%$ & $25 \%$ & \\
\hline Depressive disorder & $41 \%$ & $38 \%$ & $54 \%$ & $15 \%$ & \\
\hline Anxiety disorders & $24 \%$ & $29 \%$ & $20 \%$ & $20 \%$ & \\
\hline Personality disorders & $6 \%$ & $3 \%$ & $8 \%$ & $9 \%$ & \\
\hline Number of drugs & 2,308 & $\mathrm{I}, \mathrm{II}$ & 874 & 317 & \\
\hline Psychotropic drugs & $1.8 \pm 0.8$ & $1.9 \pm 1.1$ & $1.7 \pm 0.8$ & $1.6 \pm 0.8$ & $0.00 \mathrm{I}^{\mathrm{b}}$ \\
\hline One drug & $49 \%$ & $49 \%$ & $46 \%$ & $55 \%$ & \\
\hline Two drugs & $33 \%$ & $26 \%$ & $41 \%$ & $29 \%$ & \\
\hline Three drugs & $12 \%$ & $14 \%$ & $9 \%$ & $15 \%$ & \\
\hline Four drugs & $4 \%$ & $7 \%$ & $3 \%$ & $1 \%$ & \\
\hline Five or more drugs & $2 \%$ & $4 \%$ & $1 \%$ & $0 \%$ & \\
\hline Type of drug & & & & & $0.000^{\mathrm{b}}$ \\
\hline Antipsychotics & $22 \%$ & $19 \%$ & $18 \%$ & $46 \%$ & \\
\hline Mood stabilizers & $13 \%$ & $11 \%$ & $14 \%$ & $13 \%$ & \\
\hline Antidepressants & $37 \%$ & $35 \%$ & $49 \%$ & $12 \%$ & \\
\hline Antianxiety & $28 \%$ & $35 \%$ & $19 \%$ & $29 \%$ & \\
\hline Sidorkiewicz adherence tool & & & & & $0.000^{\mathrm{b}}$ \\
\hline High adherence & $44 \%$ & $56 \%$ & $48 \%$ & $49 \%$ & \\
\hline Good adherence & $7 \%$ & $8 \%$ & $4 \%$ & $7 \%$ & \\
\hline Moderate adherence & $15 \%$ & $6 \%$ & $13 \%$ & $11 \%$ & \\
\hline Poor adherence & $12 \%$ & $16 \%$ & $6 \%$ & $13 \%$ & \\
\hline Very poor adherence & $6 \%$ & $6 \%$ & $7 \%$ & $6 \%$ & \\
\hline Discontinuation & $16 \%$ & $18 \%$ & $22 \%$ & $14 \%$ & \\
\hline Adherence & & & & & $0.145^{\mathrm{b}}$ \\
\hline Yes & $67 \%$ & $66 \%$ & $69 \%$ & $64 \%$ & \\
\hline No & $33 \%$ & $34 \%$ & $31 \%$ & $36 \%$ & \\
\hline DAI- 10 & $3.6 \pm 3.8$ & $2.5 \pm 4.0$ & $4.7 \pm 3.0$ & $3.6 \pm 3.8$ & $0.000^{b}$ \\
\hline Pharmacophobic (range -10 to 0 ) & $23 \%$ & $35 \%$ & $9 \%$ & $23 \%$ & \\
\hline Pharmacophilic (range $>0$ to 10 ) & $77 \%$ & $65 \%$ & $91 \%$ & $77 \%$ & \\
\hline BMQ-Necessity (range I-5) & $3.5 \pm 0.9$ & $3.5 \pm 1.0$ & $3.6 \pm 0.7$ & $3.4 \pm 1.0$ & $0.002^{\mathrm{a}}$ \\
\hline BMQ-Concern (range I-5) & $3.0 \pm 1.0$ & $2.8 \pm 1.1$ & $3.3 \pm 0.7$ & $2.8 \pm 1.0$ & $0.000^{\mathrm{a}}$ \\
\hline Attitudinal group & & & & & $0.043^{b}$ \\
\hline Skeptical (low necessity-high concern) & $27 \%$ & $30 \%$ & $23 \%$ & $25 \%$ & \\
\hline Ambivalent (high necessity-high concern) & $27 \%$ & $25 \%$ & $30 \%$ & $28 \%$ & \\
\hline Indifferent (low necessity-low concern) & $19 \%$ & $18 \%$ & $19 \%$ & $19 \%$ & \\
\hline Accepting (high necessity-low concern) & $27 \%$ & $27 \%$ & $28 \%$ & $28 \%$ & \\
\hline
\end{tabular}

Notes: aStudent's t-test; ' chi-square. Data presented as mean \pm SD or \%.

Abbreviations: DAI-10, Drug Attitude Inventory - 10 Item; BMQ, Beliefs about Medicines Questionnaire.

are not presented but are summarized in Table 5. As in the logistic regression, the correct classification of adherent patients was very reasonable, ranging from $85 \%-90 \%$, while that for the non-adherent patients ranged from $23 \%-46 \%$.
The CHAID indicated that the most non-adherent group was $56 \%$ of skeptical and pharmacophobic patients in Spain, $56 \%$ of pharmacophobic patients in Venezuela, and $60 \%$ of skeptical patients in Argentina. 
Table 2 Analyses of the Necessity-Concerns Framework variables by type of psychoactive drug and country of origin

\begin{tabular}{|c|c|c|c|c|c|c|}
\hline & \multicolumn{2}{|c|}{ BMQ-specific } & \multicolumn{4}{|c|}{ Attitudinal group } \\
\hline & Necessity & Concern & Skeptical (\%) & Ambivalent (\%) & Indifferent (\%) & Accepting (\%) \\
\hline \multicolumn{7}{|l|}{ Spain } \\
\hline Antipsychotics & $3.7 I \pm I .0$ & $2.6 I \pm I . I$ & 22 & 23 & 15 & 40 \\
\hline Mood stabilizers & $3.82 \pm 0.92$ & $2.74 \pm 1.1$ & 19 & 32 & 14 & 35 \\
\hline Antidepressants & $3.37 \pm 0.98$ & $2.76 \pm 1.0$ & 32 & 21 & 23 & 24 \\
\hline Antianxiety & $3.38 \pm 1.1$ & $2.93 \pm 1.0$ & 35 & 28 & 18 & 20 \\
\hline \multirow[t]{2}{*}{ Total } & $3.49 \pm 1.0$ & $2.79 \pm 1.1$ & 30 & 25 & 19 & 27 \\
\hline & $p<0.000$ & $p=0.009$ & \multicolumn{4}{|c|}{$\chi^{2}=54.500, p<0.000$} \\
\hline \multicolumn{7}{|l|}{ Argentina } \\
\hline Antipsychotics & $3.56 \pm 0.79$ & $3.47 \pm 0.85$ & 28 & 35 & 14 & 24 \\
\hline Mood stabilizers & $3.63 \pm 0.77$ & $3.25 \pm 0.85$ & 29 & 30 & 15 & 27 \\
\hline Antidepressants & $3.63 \pm 0.66$ & $3.24 \pm 0.71$ & 18 & 30 & 21 & 31 \\
\hline Antianxiety & $3.56 \pm 0.74$ & $3.32 \pm 0.65$ & 29 & 28 & 21.0 & 23 \\
\hline \multirow[t]{2}{*}{ Total } & $3.60 \pm 0.7$ & $3.30 \pm 0.7$ & 24 & 30 & 19 & 28 \\
\hline & $p=0.756$ & $p=0.021$ & \multicolumn{4}{|c|}{$\chi^{2}=23.173, p=0.026$} \\
\hline \multicolumn{7}{|l|}{ Venezuela } \\
\hline Antipsychotics & $3.61 \pm 1.1$ & $2.59 \pm 1.0$ & 19 & 25 & 16 & 40 \\
\hline Mood stabilizers & $3.35 \pm 1.0$ & $2.59 \pm 0.90$ & 19 & 30 & 23 & 28 \\
\hline Antidepressants & $2.92 \pm 1.2$ & $2.75 \pm 1.0$ & 21 & 26 & 40 & 13 \\
\hline Antianxiety & $3.28 \pm 1 . I$ & $3.04 \pm 0.98$ & 37 & 32 & 14 & 18 \\
\hline \multirow[t]{2}{*}{ Total } & $3.40 \pm 1.1$ & $2.73 \pm 1.0$ & 25 & 28 & 19 & 29 \\
\hline & $p=0.006$ & $p=0.023$ & \multicolumn{4}{|c|}{$\chi^{2}=35.185, p<0.000$} \\
\hline
\end{tabular}

Note: Data presented as mean \pm SD or $\%$.

Abbreviation: BMQ, Beliefs about Medicines Questionnaire.

Box I The most relevant descriptive findings in three countries

- A great majority of psychiatric outpatients ( $>64 \%$ ), independent of their country of origin, expressed a positive attitude toward their prescribed psychotropic medications, according to scores registered by the DAI-I0.

- The Argentinian patients were those who self-reported a greater necessity for their prescribed psychotropic drugs as well as a greater concern about their use, while the Venezuelan patients self-reported the least necessity and concern about their possible side effects.

- The Spanish and Venezuelan patients registered significant differences on the scales of necessity and concern regarding the various psychotropic drugs consumed.

- For Spanish patients, the higher necessity drugs were self-reported to be mood stabilizers, while in Venezuelan patients the higher necessity drugs were antipsychotics. Both countries shared higher concern about benzodiazepines.

- The Argentine patients did not register significant differences in their perception of the necessity of the various psychotropic drugs, although they registered differences in their concerns about adverse effects.

- The greatest concern of the Argentinians was with antipsychotic drugs.

- The Spanish patients were the most skeptical about their prescribed treatment while the Venezuelans were those who most accepted their prescribed treatment.

- Benzodiazepines generated the greatest skepticism in Spanish and Venezuelans, while for the Argentineans, the mood stabilizer drugs registered greater skepticism.

- On the other hand, antipsychotics were the drugs most accepted by Spanish and Venezuelans, while for the Argentines it was antidepressants.

Abbreviation: DAl-10, Drug Attitude Inventory - 10 Item.
In summary, the results of the logistic regression analysis and the CHAID segmentation analysis were remarkably similar and highlight the role of pharmacophobia and skepticism in poor adherence with some variations across these three countries regarding their significance (or lack thereof) and their effect sizes.

\section{Discussion}

\section{How culture influences health beliefs}

All cultures have systems of health beliefs to explain what causes illness, how it can be cured or treated, and who should be involved in the process. ${ }^{26}$ Because values and behavior are largely socially conditioned, understanding the cultural factors that influence treatment-seeking behaviors and treatment adherence is crucial for maximizing health outcomes. ${ }^{27}$

\section{Previously published studies}

A considerable number of studies have investigated public attitudes toward psychiatric treatment. ${ }^{28}$ There have also been studies that investigated psychiatric patients' beliefs and attitudes toward their psychiatric treatment. ${ }^{18,29-31}$ However, this is the first study that has explored the beliefs and attitudes of psychiatric patients toward prescribed treatment, and their influence on treatment adherence, from a cross-cultural perspective in Spanish-speaking countries. 
Table 3 Analyses of the DAI-10 and BMQ according to selfreported adherence and by country

\begin{tabular}{|c|c|c|c|c|}
\hline & Global & Non-adherent & Adherent & $x^{2}$ \\
\hline \multicolumn{5}{|l|}{ Spain } \\
\hline DAI-I0 score & $2.5 \pm 4.0$ & $1.7 \pm 4.2$ & $3.2 \pm 3.6$ & 0.000 \\
\hline Pharmacophobic & $35 \%$ & $41 \%$ & $28 \%$ & $\begin{array}{l}17.466, \\
p<0.000\end{array}$ \\
\hline Pharmacophilic & $65 \%$ & $59 \%$ & $72 \%$ & \\
\hline BMQ-Necessity & $3.5 \pm 1.0$ & $3.2 \pm 110$ & $3.7 \pm 1.0$ & 0.000 \\
\hline BMQ-Concern & $2.8 \pm 1.1$ & $3.0 \pm 1.1$ & $2.7 \pm 1.0$ & 0.000 \\
\hline Skeptical & $29 \%$ & $38 \%$ & $25 \%$ & $\begin{array}{l}22.375, \\
p<0.000\end{array}$ \\
\hline Ambivalent & $25 \%$ & $23 \%$ & $26 \%$ & \\
\hline Indifferent & $19 \%$ & $19 \%$ & $19 \%$ & \\
\hline Accepting & $27 \%$ & $21 \%$ & $30 \%$ & \\
\hline \multicolumn{5}{|l|}{ Argentina } \\
\hline DAl-I0 score & $4.7 \pm 3.0$ & $3.9 \pm 4.1$ & $5.2 \pm 2.3$ & 0.000 \\
\hline Pharmacophobic & $9 \%$ & $15 \%$ & $5 \%$ & $\begin{array}{l}24.714, \\
p<0.000\end{array}$ \\
\hline Pharmacophilic & $91 \%$ & $85 \%$ & $95 \%$ & \\
\hline BMQ-Necessity & $3.6 \pm 0.7$ & $3.2 \pm 0.7$ & $3.7 \pm 0.7$ & 0.000 \\
\hline BMQ-Concern & $3.3 \pm 0.7$ & $3.6 \pm 0.8$ & $3.2 \pm 0.7$ & 0.000 \\
\hline Skeptical & $23 \%$ & $46 \%$ & $13 \%$ & $\begin{array}{l}|18.7| 2, \\
p<0.000\end{array}$ \\
\hline Ambivalent & $30 \%$ & $24 \%$ & $33 \%$ & \\
\hline Indifferent & $19 \%$ & $17 \%$ & $20 \%$ & \\
\hline Accepting & $28 \%$ & $13 \%$ & $34 \%$ & \\
\hline \multicolumn{5}{|l|}{ Venezuela } \\
\hline DAI-I0 score & $3.6 \pm 3.8$ & $2.3 \pm 4.1$ & $4.5 \pm 3.5$ & 0.000 \\
\hline Pharmacophobic & $23 \%$ & $35 \%$ & $15 \%$ & $\begin{array}{l}15.962, \\
p<0.000\end{array}$ \\
\hline Pharmacophilic & $77 \%$ & $65 \%$ & $85 \%$ & \\
\hline BMQ-Necessity & $3.4 \pm 1.0$ & $3.1 \pm 1.1$ & $3.5 \pm 1.0$ & 0.001 \\
\hline BMQ-Concern & $2.8 \pm 1.0$ & $2.9 \pm 1.0$ & $2.6 \pm 1.0$ & 0.017 \\
\hline Skeptical & $25 \%$ & $34 \%$ & $20 \%$ & $\begin{array}{l}11.309 \\
p<0.010\end{array}$ \\
\hline Ambivalent & $28 \%$ & $26 \%$ & $29 \%$ & \\
\hline Indifferent & $19 \%$ & $20 \%$ & $18 \%$ & \\
\hline Accepting & $28 \%$ & $20 \%$ & $33 \%$ & \\
\hline
\end{tabular}

Note: Data presented as mean \pm SD or $\%$.

Abbreviations: BMQ, Beliefs about Medicines Questionnaire; DAI-10, Drug Attitude Inventory - 10 Item.

Box 2 The most relevant findings of analyses of DAI- 10 and BMQ

- A look at the most crucial percentage of tables relevant for the planned multivariate analyses indicated:

- An average lack of adherence of $33 \%$ (range $31 \%-36 \%$ )

- An average pharmacophobia of $23 \%$ (range $9 \%-35 \%$ )

- An average skeptical group of $27 \%$ (range $23 \%-30 \%$ )

- Regarding patient nationalities:

- Venezuelans appear to be relatively similar to the Spaniards from the Canary Islands

- Argentinians appear much more pharmacophilic than the other two countries with a very small percentage of patients ( $9 \%)$ classified as pharmacophobic

Abbreviations: BMQ, Beliefs about Medicines Questionnaire; DAI-10, Drug Attitude Inventory - 10 Item.
Contribution to the literature from our results

According to our results, sociodemographic and clinical variables other than sex and age (see footnote a of Table 4) have a limited effect on psychiatric patients' adherence to their prescribed psychopharmacological treatment, regardless of their country of origin. However, cultural differences influenced their attitudes and contributed to significant differences in the univariate analyses of psychiatric drug treatment, beliefs about treatment necessity and concern, and treatment adherence. As expected in the univariate analyses for each country, there were different mean scores on the DAI-10 and mean BMQ-Necessity and Concerns subscales; however, the percentages of non-adherents and skeptical patients were relatively similar in the three countries. Argentinian patients appeared to have a very low level of pharmacophobia when compared with the other two countries. The multivariate analyses revealed that, in effect, pharmacophobia and skepticism appear to have an important association with poor adherence, but skepticism has a greater role in Argentina. By combining univariate and multivariate analyses, we identify two major profiles. Argentinian psychiatric patients had a lot of faith in psychotropic drugs, as was evidenced by high values on the DAI-10 and by the inconsistent effects of pharmacophobia in general. Furthermore, in Argentina, non-adherence appeared to be mainly driven by skeptical patients, those who perceive a specific medication as unnecessary and who had high concern for its ADRs, highlighting the relevance of the Necessity-Concerns Framework..$^{18}$ On the other hand, Spanish and Venezuelan psychiatric patients shared a profile, that of pharmacophobia contributing to non-adherence. ${ }^{14}$

\section{A possible explanation for the similarities between the Spanish and Venezuelan results}

During the colonial era, and until the end of the Second World War, most of the European immigrants who arrived in Venezuela were from the Canary Islands and their cultural impact was significant, influencing both the development of the Spanish language in the country as well as gastronomy and customs. In fact, Venezuela is considered to be the country with the largest Canarian population; it is common to say both on the islands and in Venezuela that "Venezuela is the eighth island of the Canary Islands". ${ }^{32}$

\section{Strengths and limitations}

The strengths of this ethnopsychopharmacological study of beliefs and attitudes toward psychiatric drug treatment 
Table 4 Binary logistic regression analyses in the global sample and by country (variables entered: gender, age, pharmacophobia, and skepticism) ${ }^{\mathrm{a}}$

\begin{tabular}{|c|c|c|c|c|}
\hline Variable & Global sample & Spain & Argentina & Venezuela \\
\hline \multicolumn{5}{|l|}{ Sex ${ }^{b}$} \\
\hline OR $(\mathrm{Cl})$ & $1.35(1.12-1.61)$ & $\mathrm{I} .17(0.9 \mathrm{I}-\mathrm{I} .5 \mathrm{I})$ & $1.45(\mathrm{I} .04-2.0 \mathrm{I})$ & $1.90(1.15-3.14)$ \\
\hline$p$-value & 0.001 & 0.22 & 0.03 & 0.012 \\
\hline$\chi^{2}$ & $0.30 / 0.1 / 10.12 / 1$ & $0.15 / 0.13 / 1.51 / 1$ & $0.37 / 0.17 / 4.81 / 1$ & $0.65 / 0.26 / 6.38 / I$ \\
\hline \multicolumn{5}{|l|}{ Age } \\
\hline OR (Cl) & $1.02(1.01-1.03)$ & $1.01(1.00-1.02)$ & $1.02(1.01-1.03)$ & $1.03(1.01-1.04)$ \\
\hline$p$-value & $<0.001$ & 0.02 & $<0.001$ & 0.01 \\
\hline$\chi^{2}$ & $0.02 / 0.003 / 31.437 \mid$ & $0.01 / 0.005 / 5.26 / 1$ & $0.02 / 0.005 / 17.75 / I$ & $0.02 / 0.01 / 6.58 / 1$ \\
\hline \multicolumn{5}{|l|}{ Pharmacophobia $^{c}$} \\
\hline $\mathrm{OR}(\mathrm{Cl})$ & $1.66(1.34-2.06)$ & $1.52(1.16-1.99)$ & $2.17(I .27-3.7 I)$ & $2.6 \mathrm{I}(1.43-4.76)$ \\
\hline$p$-value & $<0.001$ & 0.003 & 0.005 & 0.002 \\
\hline$\chi^{2}$ & $0.30 / 0.09 / 10.1 / 1$ & $0.42 / 0.14 / 9.03 / 1$ & $0.77 / 0.27 / 7.95 / 1$ & $0.96 / 0.30 / 9.81 / 1$ \\
\hline \multicolumn{5}{|l|}{ Skepticism ${ }^{c}$} \\
\hline $\mathrm{OR}(\mathrm{Cl})$ & $2.22(I .82-2.7 I)$ & $1.56(1.18-2.06)$ & $4.39(3.10-6.22)$ & $1.40(0.79-2.50)$ \\
\hline$p$-value & $<0.001$ & 0.002 & $<0.00 \mathrm{I}$ & 0.25 \\
\hline$\chi^{2}$ & $0.80 / 0.10 / 60.73 / I^{d}$ & $0.44 / 0.14 / 9.93 / I^{d}$ & $1.48 / 0.18 / 69.8 / I^{d}$ & $0.34 / 0.29 / 1.33 / \mathrm{I}^{\mathrm{d}}$ \\
\hline \multicolumn{5}{|l|}{ Model summary } \\
\hline 2 Log likelihood & $2,747.989$ & $1,393.193$ & 939.572 & 376.486 \\
\hline Cox and Snell $R^{2}$ & 0.072 & 1.032 & 0.145 & 0.101 \\
\hline Nagelkerke $R^{2}$ & 0.100 & 1.044 & 0.205 & 0.139 \\
\hline Hosmer and Lemeshow & 0.349 & 0.206 & 0.002 & 0.340 \\
\hline
\end{tabular}

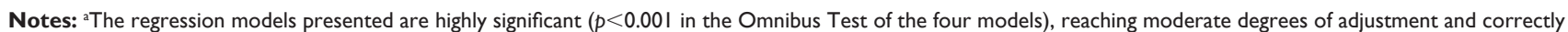
classifying 92\% of the adherence cases (Spain: 95\%; Argentina: 90\%; Venezuela: 90\%), 70\% of the total (Spain: 66\%; Argentina: 74\%; Venezuela: 70\%), and only 23\% of the cases with non-adherence (Spain: 10\%; Argentina: 39\%; Venezuela: 33\%). Neither educational level nor diagnoses were included since they did not register significant differences in univariante analysis; ${ }^{b} 0=$ male and $\mathrm{I}=$ female; ${ }^{\mathrm{c}} \mathrm{O}=\mathrm{no}$ and $\mathrm{I}=$ yes; ${ }^{\mathrm{d}} \chi^{2}$ is a chi-square test, which is summarized by using four statistical parameters: beta/standard error/Wald/ degrees of freedom.

Abbreviations: $\mathrm{Cl}$, confidence interval; OR, odds ratio.

among Spanish-speaking psychiatric patients from the three countries include the large number of psychiatric patients participating in the study; the large number of sociodemographic, clinical, and psychological variables analyzed; and the statistics employed. However, some limitations concerning the methodology used need to be considered. First, it cannot be ignored that the patients studied are from convenience samples of consecutive psychiatric outpatients, which may not be representative of the entire population of psychiatric patients. We used the words Spanish, Argentinian, or Venezuelan to simplify the description rather than to imply that these samples are representative of all psychiatric patients of that country. Future studies will need to explore whether these samples of convenience properly represent the psychiatric patients in their respective countries and explore the differences between patients in the public and private health systems.

Second, all questionnaires used were self-reports and therefore may be subject to self-presentation and recall biases,$^{33}$ with some psychiatric patients claiming higher adherence rates than they really have. However, these biases do not question the finding that attitudes and beliefs were related to adherence, since there is no evidence that these biases would be systematically associated with medication beliefs. ${ }^{18} \mathrm{~A}$ third and final limitation is that the classification of lack of adherence was less accurate than the classification of adherence, indicating that other cognitive measures potentially influencing poor adherence ${ }^{11}$ need to be explored by future studies.

\section{Conclusion}

The univariate analyses indicated that various patient attitudes and beliefs influenced how psychiatric patients adhered to their prescribed treatment in each of these three Spanishspeaking countries. On the other hand, the two multivariate analyses showed that pharmacophobia and skepticism are important patient attitudes and beliefs in non-adherence. Pharmacophobia, in general, stands out as a major factor associated with non-adherence (Canary Islands in Spain and Venezuela), but when pharmacophobia is rare (Argentina), the balance between perceived necessity and concern about ADRs leading to skepticism about specific medications may become the most important variable associated with poor adherence in psychiatric patients. 


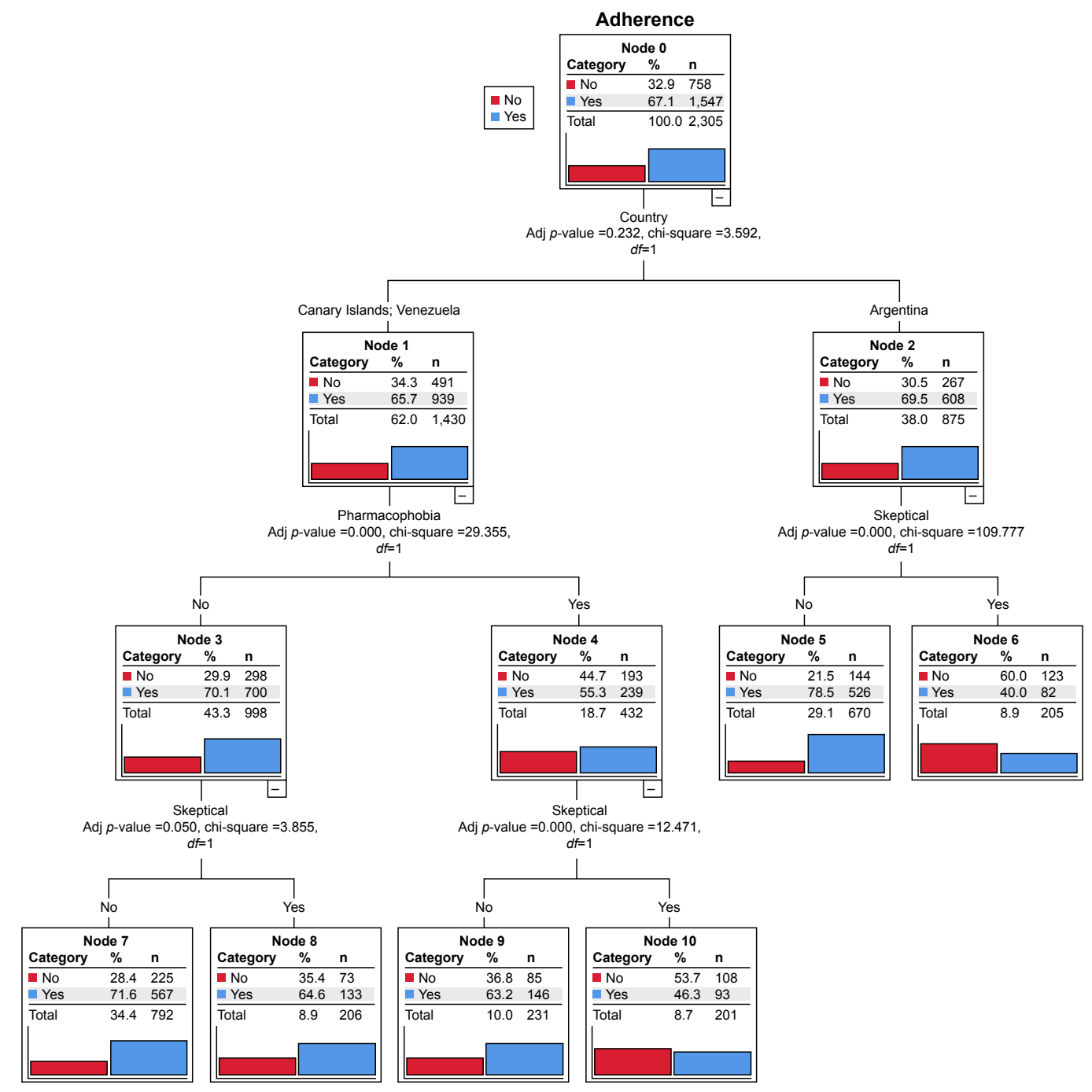

Figure I CHAID diagram of the tree with five predictors (country, sex, age, pharmacophobia, and skepticism) and adherence to prescribed treatment as the outcome variable in the global sample of psychiatric outpatients.

Abbreviations: Adj, adjusted; CHAID, chi-squared automatic interaction detector.

Table 5 Summary of results from CHAID decision trees for each country with their adherence classification

\begin{tabular}{llll}
\hline Results & Spain & Argentina & Venezuela \\
\hline Percent correct & & & \\
$\quad$ Non-adherent & $23 \%$ & $46 \%$ & $35 \%$ \\
Adherent & $90 \%$ & $87 \%$ & $85 \%$ \\
$\quad$ Overall & $67 \%$ & $74 \%$ & $67 \%$ \\
Highest & $70 \%$ in non- & $79 \%$ in non- & $70 \%$ in non- \\
adherence $^{\text {a }}$ & skeptical & skeptical & pharmacophobic \\
Highest non- $^{\text {adherence }}$ & $56 \%$ in skeptical and & $60 \%$ in & $56 \%$ in \\
Risk estimate $^{\mathrm{a}}$ & pharmacophobic & skeptical & pharmacophobic \\
Standard error & 0.330 & 0.258 & 0.330 \\
\hline
\end{tabular}

Notes: aPercentages in these two rows are inverse (eg, in Spain the group with the highest adherence was the non-skeptical patient group, including $70 \%$ who were adherent and $30 \%$ non-adherent; the group with the highest non-adherence was the skeptical and pharmacophobic patient group, including $56 \%$ who were non-adherent and $44 \%$ adherent).

Abbreviation: CHAID, chi-squared automatic interaction detector.

\section{Acknowledgments}

No commercial organizations had any role in the completion or publication of this study. The authors acknowledge Lorraine Maw, MA, at the Mental Health Research Center at Eastern State Hospital, Lexington, KY, USA, who helped in editing this article. The authors also acknowledge the reviewers who helped them to improve this article.

\section{Disclosure}

The authors report no conflicts of interest in this work.

\section{References}

1. Chen $\mathrm{CH}$, Chen $\mathrm{CY}$, Lin KM. Ethnopsychopharmacology. Int Rev Psychiatry. 2008;20(5):452-459. 
2. Ninnemann KM. Variability in the efficacy of psychopharmaceuticals: contributions from pharmacogenomics, ethnopsychopharmacology, and psychological and psychiatric anthropologies. Cult Med Psychiatry. 2012;36(1):10-25.

3. Silva H. Ethnopsychopharmacology and pharmacogenomics. $A d v$ Psychosom Med. 2013;33:88-96.

4. Wood AJ, Zhou HH. Ethnic differences in drug disposition and responsiveness. Clin Pharmacokinet. 1991;20(5):350-373.

5. Schomerus G, Matschinger H, Baumeister SE, Mojtabai R, Angermeyer MC. Public attitudes towards psychiatric medication: a comparison between United States and Germany. World Psychiatry. 2014;13(3):320-321.

6. McHugh RK, Whitton SW, Peckham AD, Welge JA, Otto MW. Patient preference for psychological vs pharmacologic treatment of psychiatric disorders: a meta-analytic review. J Clin Psychiatry. 2013; 74(6):595-602.

7. Olfson M, Kroenke K, Wang S, Blanco C. Trends in office-based mental health care provided by psychiatrists and primary care physicians. J Clin Psychiatry. 2014;75(3):247-253.

8. $\mathrm{Ng} \mathrm{CH}$, Klimidis S. Cultural factors and the use of psychotropic medications. In: $\mathrm{Ng} \mathrm{CH}$ et al, editors. Ethno-psychopharmacology: Advances in Current Practice. Cambridge: Cambridge University Press; 2008:123-134.

9. GBD 2015 Healthcare Access and Quality Collaborators. Healthcare access and quality index based on mortality from causes amenable to personal health care in 195 countries and territories, 1990-2015: a novel analysis from the Global Burden of Disease Study 2015. Lancet. 2017;5:390(10091):231-266.

10. Bekker FJ, Hentschel U, Fujita M. Basic cultural values and differences in attitudes towards health, illness and treatment preferences within a psychosomatic frame of reference. Psychother Psychosom. 1996;65(4):191-198.

11. De Las Cuevas C, de Leon J. Reviving research on medication attitudes for improving pharmacotherapy: focusing on adherence. Psychother Psychosom. 2017;86(2):73-79.

12. de Leon J, De Las Cuevas C. The art of pharmacotherapy: reflections on pharmacophobia. J Clin Psychopharmacol. 2017;37(2):131-137.

13. Hogan TP, Awad AG, Eastwood R. A self-report scale predictive of drug compliance in schizophrenics: reliability and discriminative validity. Psychol Med. 1983;13(1):177-183.

14. De las Cuevas C, Peñate W. Explaining pharmacophobia and pharmacophilia in psychiatric patients: relationship with treatment adherence. Hum Psychopharmacol. 2015;30(5):377-383.

15. Sibitz I, Katschnig H, Goessler R, Unger A, Amering M. Pharmacophilia and pharmacophobia: determinants of patients' attitudes towards antipsychotic medication. Pharmacopsychiatry. 2005;38(3):107-112.

16. Horne R, Weinman J. Patients' beliefs about prescribed medicines and their role in adherence to treatment in chronic physical illness. J Psychosom Res. 1999;47(6):555-567.

17. De las Cuevas C, Rivero-Santana A, Perestelo-Perez L, GonzalezLorenzo M, Perez-Ramos J, Sanz EJ. Adaptation and validation study of the Beliefs about Medicines Questionnaire in psychiatric outpatients in a community mental health setting. Hum Psychopharmacol. 2011; 26(2):140-146.
18. Horne R, Chapman SC, Parham R, Freemantle N, Forbes A, Cooper V. Understanding patients' adherence-related beliefs about medicines prescribed for long-term conditions: a meta-analytic review of the necessity-concerns framework. PLoS One. 2013;2:8(12): e80633.

19. De las Cuevas C, Peñate W, Cabrera C. Are acceptance and skepticism determinant factors for adherence to drug treatment in psychiatric patients? J Clin Psychopharmacol. 2016;36(6):724-725.

20. Aikens JE, Nease DE Jr, Nau DP, Klinkman MS, Schwenk TL. Adherence to maintenance-phase antidepressant medication as a function of patient beliefs about medication. Ann Fam Med. 2005; 3(1):23-30.

21. Menckeberg TT, Bouvy ML, Bracke M, et al. Beliefs about medicines predict refill adherence to inhaled corticosteroids. J Psychosom Res. 2008(1);64:47-54.

22. Sidorkiewicz S, Tran VT, Cousyn C, Perrodeau E, Ravaud P. Development and validation of an instrument to assess treatment adherence for each individual drug taken by a patient. BMJ Open. 2016; 6(5): 010510.

23. De las Cuevas C, Peñate W, García de Cecilia JM, de Leon J. Predictive validity of the Spanish version of the Sidorkiewicz instrument for assessing treatment adherence for each individual drug taken by a psychiatric patient. Int J Clin Health Psychol. Epub December 11, 2017.

24. IBM Corp. IBM SPSS Statistics for Mac, Version 24.0. Armonk, NY: IBM Corp.; 2016.

25. Chan F, Cheing G, Chan JY, Rosenthal DA, Chronister J. Predicting employment outcomes of rehabilitation clients with orthopedic disabilities: a CHAID analysis. Disabil Rehabil. 2006;28(5):257-270.

26. McLaughlin LA, Braun KL. Asian and Pacific Islander cultural values: considerations for health care decision making. Health Soc Work. 1998;23(2):116-126.

27. Napier AD, Ancarno C, Butler B, et al. Culture and health. Lancet. 2014;384(9954):1607-1639.

28. Angermeyer MC, van der Auwera S, Carta MG, Schomerus G. Public attitudes towards psychiatry and psychiatric treatment at the beginning of the 21st century: a systematic review and meta-analysis of population surveys. World Psychiatry. 2017;16(1):50-61.

29. Brown C, Battista DR, Bruehlman R, Sereika SS, Thase ME, DunbarJacob J. Beliefs about antidepressant medications in primary care patients: relationship to self-reported adherence. Med Care. 2005; 43(12):1203-1207.

30. De las Cuevas C, Sanz EJ. Attitudes toward psychiatric drug treatment: the experience of being treated. Eur J Clin Pharmacol. 2007;63(11): 1063-1067.

31. Jónsdóttir H, Friis S, Horne R, Pettersen KI, Reikvam A, Andreassen OA. Beliefs about medications: measurement and relationship to adherence in patients with severe mental disorders. Acta Psychiatr Scand. 2009;119(1):78-84.

32. Diaz-Miranda E. Venezuela, la octava isla canaria. AmerindiaDeutschland. 2015;1:36-39.

33. Garfield S, Clifford S, Eliasson L, Barber N, Willson A. Suitability of measures of self-reported medication adherence for routine clinical use: a systematic review. BMC Med Res Methodol. 2011;11:149.
Patient Preference and Adherence

\section{Publish your work in this journal}

Patient Preference and Adherence is an international, peer-reviewed, open access journal that focuses on the growing importance of patient preference and adherence throughout the therapeutic continuum. Patient satisfaction, acceptability, quality of life, compliance, persistence and their role in developing new therapeutic modalities and compounds to optimize

\section{Dovepress}

clinical outcomes for existing disease states are major areas of interest for the journal. This journal has been accepted for indexing on PubMed Central. The manuscript management system is completely online and includes a very quick and fair peer-review system, which is all easy to use. Visit http://www. dovepress.com/testimonials.php to read real quotes from published authors. 